\title{
Gender Difference in Event Related Potentials to Masked Emotional Stimuli in the Oddball Task
}

\author{
Eun Young Kim¹, Seung-Hwan Lee ${ }^{1,2} \bowtie$, Gewnhi Park', Sangrae Kim', \\ Imyel Kim ${ }^{3}$, Jeong-Ho Chae ${ }^{4}$ and Hyun Taek Kim ${ }^{5}$ \\ ${ }^{1}$ Clinical Emotion and Cognition Research Laboratory, Goyang, Republic of Korea \\ 2Department of Psychiatry, Inje University Ilsan Paik Hospital, Goyang, Republic of Korea \\ ${ }^{3}$ Keyo Mental Hospital, Uiwang, Republic of Korea \\ ${ }^{4}$ Department of Psychiatry, The Catholic University of Korea College of Medicine, Seoul, Republic of Korea \\ ${ }^{5}$ Department of Psychology, Korea University, Seoul, Republic of Korea
}

Objective We investigated gender differences in event-related potential (ERP) responses to subliminally presented threat-related stimuli. Methods Twenty-four participants were presented with threat-related and neutral pictures for a very brief period of time (17 ms). To explore gender differences in ERP responses to subliminally presented stimuli, we examined six ERP components [P1, N170, N250, P300, Early Posterior Negativity (EPN) and Late Positive Potential (LPP)].

Results The result revealed that only female participants showed significant increases in the N170 and the EPN in response to subliminally presented threat-related stimuli compared to neutral stimuli.

Conclusion Our results suggest that female participants exhibit greater cortical processing of subliminally presented threat-related stimuli than male participants.

Psychiatry Investig 2013;10:164-172

Key Words Threat-related stimuli, Gender, Subliminal stimuli, N170, EPN.

\section{INTRODUCTION}

More women suffer from anxiety disorders and major depressive disorder than men. ${ }^{1,2}$ Gender differences in affective disorders may result from differences in emotional processing. For example, Kemp et al. ${ }^{2}$ reported that female participants showed widespread frontal latency reductions (predominantly right sided) during the processing of emotional stimuli, whereas this result was not observed in male participants. Furthermore, emotionally unpleasant pictures elicited greater reactivity of various psychophysiological responses, such as facial EMG activity, cardiac orienting, and reflex modulation in female participants compared to male participants. ${ }^{3}$ Also, a series of neuroimaging studies revealed that male and female

Received: September 29, 2012 Revised: December 7, 2012

Accepted: December 10, 2012 Available online: May 30, 2013

$\triangle$ Correspondence: Seung-Hwan Lee, MD, PhD

Department of Psychiatry, Inje University College of Medicine, Ilsan Paik Hospital, 170 Juhwa-ro, Ilsanseo-gu, Goyang 411-706, Republic of Korea

Tel: +82-31-910-7262, Fax: +82-31-910-7268

E-mail: 1shpss@paik.ac.kr

(a) This is an Open Access article distributed under the terms of the Creative Commons Attribution Non-Commercial License (http://creativecommons.org/licenses/bync/3.0) which permits unrestricted non-commercial use, distribution, and reproduction in any medium, provided the original work is properly cited. participants showed differential activation in brain structures in response to emotional stimuli. ${ }^{4.5}$ Female participants showed greater activation in anterior limbic structures, as well as in the inferior orbitofrontal cortices, during induced sadness relative to male participants. ${ }^{67}$ However, it has been suggested that event-related potentials (ERPs), characterized by a superior temporal resolution, may be particularly useful to capture gender differences in the emotional processing across time. ${ }^{8}$

Because of biological significance, emotionally salient stimuli are thought to be processed even if presented out of conscious awareness. ${ }^{9-13}$ Indeed, evidence suggested that subliminally presented fearful faces elicited greater activation in the amygdala compared to neutral faces. ${ }^{14,15}$ Also, electrophysiological studies revealed that subliminally presented fearful stimuli elicited greater ERP responses. ${ }^{9,16-18}$ Subliminally presented fearful faces elicited an early positivity to fearful faces although its activity level is smaller than that elicited by supraliminally presented faces. ${ }^{9}$ Also, subliminally presented fearful faces elicited greater $\mathrm{N} 2$ which was associated with orienting and automatic face processing, while $\mathrm{P} 3$ was sensitive to fearful faces in supraliminal trials. ${ }^{9,17,18}$

Several ERP components are associated with the process- 
ing of facial emotional expressions: P100, N170, N250, and P300. ${ }^{19-21}$ Previous evidence suggested that the P100, reflecting the early visual processing, is modulated by emotional stimuli. ${ }^{20,22,23}$ Also, an enhanced P1 to a bar replaced a fearful face compared to when the same bar replaced a neutral face was observed over lateral occipital leads. ${ }^{24}$ The N170 is associated with facial structural processing ${ }^{25,26}$ as well as facial affective processing. ${ }^{27}$ The N250 is associated with processing familiar faces: Familiar faces elicite greater N250 at inferior temporal sites compared to unfamiliar faces. ${ }^{28,29}$ The N250 is also associated with processing the emotional content of a face. ${ }^{30}$ The P300 is considered to reflect the encoding of emotional content. ${ }^{31}$ There is some evidence suggesting gender effects on the P300: Enhanced P300 was observed in response to emotional stimuli in female participants. ${ }^{1,20}$ However, in another study, male participants had greater amplitudes of $\mathrm{P} 300 .{ }^{31} \mathrm{On}$ the other hand, Polich ${ }^{32}$ found no significant gender difference in P300 responses to auditory stimuli. Thus, there are inconsistent results regarding the gender effect on the P300.

There are two other ERP components that are modulated by emotional processing: the Early Posterior Negativity (EPN) and the Late Positive Potential (LPP). The EPN refers to negative deflection over the temporo-occipital sites within a time window between 150 (200) and $300 \mathrm{~ms}$ in response to emotional stimuli. ${ }^{33-35}$ Greater EPNs were observed in response to negative faces compared to positive and neutral faces over lateral posterior and occipital areas. ${ }^{36}$ The LPP refers to positive potentials that become evident approximately after P300 peak and is typically maximal at midline and parietal electrodes. ${ }^{37,38}$ The larger LPP is typically observed for pleasant and unpleasant compared to neutral stimuli. ${ }^{37,38}$ It has been suggested that the LPP is associated with sustained attention and the elaborative processing of affective stimuli. ${ }^{39}$

The goal of the current study is to examine whether there are gender differences in ERP responses to subliminally presented fearful stimuli in the modified oddball task. ${ }^{21}$ We examined several ERP components such as the P100, N170, N250, P300, EPN and LPP typically associated with emotional processing. We hypothesized that women should show greater amplitude of ERP to affectively significant stimuli presented subliminally, thereby making more hypervigilant responses. We further hypothesized that these hypervigilant responses would occur in earlier ERP components (P100, N170, and EPN) rather than in later ERP components (N250, P300, and LPP).

\section{METHODS}

\section{Participants}

A total of 24 volunteers (12 female) were recruited from the local community through local newspapers and posters. Male and female participants did not differ statistically in ages (41士 5.3 years for male; $40 \pm 3.5$ years for female) and education duration ( $15 \pm 1.7$ years for the male; $14 \pm 1.9$ years for the female).

All participants were right-handed, as determined by asking about the hand used for writing and other precise motor skills. All participants had normal or corrected to normal vision (20/20 visual acuity). People with a history of vision disorders or dysfunctions or neurological or psychiatric disorders were excluded from the study. Anxiety and depressive symptoms were screened by self-report scales: Beck Depression Inventory, ${ }^{40}$ and Beck Anxiety Inventory. ${ }^{41}$

We included only those whose BDI and BAI scores were low - below ten, which allowed us to recruit the participants who were not suffering from anxiety and depressive symptoms. Furthermore, all participants were screened by an interview with a clinician who used the Structured Clinical Interview for DSM-IV Axis II Disorders, ${ }^{42}$ and were excluded if they had any of personality disorders. All subjects provided written informed consent to participate; the form was approved by the Institutional Review Board of Inje University Ilsan Paik Hospital.

\section{Stimuli and procedure}

Six pictures (three pairs) were chosen from the International Affective Pictures System (IAPS). ${ }^{43}$ The IAPS picture numbers were as follows: 2055.1, 2352.2, 3005.1 for the threat-related category and 2055.2, 2352.1, 3005.2 for the neutral category. The three pairs of matched picture set were 2055.1 vs. 2055.2, 2352.2 vs. 2352.1 , and 3005.1 vs. 3005.2 . Picture pairs are equivalent in arousal level, but are significantly different in valence (Table 1). And there were differences in ratings for the selected stimuli between male and female raters. The mean of normative valence ratings of three pairs were $3.15 \pm 1.84$ vs. $6.40 \pm 1.75,2.09 \pm 1.75$ vs. $7.27 \pm 1.79$, and $1.63 \pm 1.19$ and $5.98 \pm$ 1.90 , respectively. ${ }^{43}$ The mean of normative arousal ratings of three pairs were $4.95 \pm 2.11$ vs. $4.45 \pm 2.18,6.25 \pm 2.10$ vs. $5.16 \pm$ $2.17,6.20 \pm 2.54$ vs. $4.84 \pm 2.18$, respectively. ${ }^{43}$ Ratings of arousal and valence are scored such that 9 represents a high rating for each dimension (i.e., high pleasure, high arousal) and 1 represents a low rating for each dimension (i.e., low pleasure, low arousal). A value of 5 is considered a medium rating on this scale. Selected pictures were pictures of a man or woman with different facial expressions in a certain background. For example, a neutral picture consisted of a man or woman with a neutral facial expression standing in a certain background image, whereas the counterpart threat-related picture consisted of a man or woman with a disfigured face (e.g., a smashed face, a severely wounded face, or a dead face) in the same 
Table 1. Normative data of valence and arousal in response to pictures from the International Affective Pictures Systems that were used in the present study

\begin{tabular}{|c|c|c|c|c|c|c|c|}
\hline \multirow{2}{*}{ Description } & \multirow{2}{*}{$\begin{array}{l}\text { Slide } \\
\text { No. }\end{array}$} & \multicolumn{2}{|c|}{ All subjects } & \multicolumn{2}{|c|}{ Male subjects } & \multicolumn{2}{|c|}{ Female subjects } \\
\hline & & Valence mean & Arousal mean & Valence mean & Arousal mean & Valence mean & Arousal mean \\
\hline Man in pool & 2055.1 & $3.15 \pm 1.84$ & $4.95 \pm 2.11$ & $3.51 \pm 1.74$ & $4.61 \pm 2.02$ & $2.84 \pm 1.89$ & $5.23 \pm 2.15$ \\
\hline Man in pool & 2055.2 & $6.40 \pm 1.75$ & $4.45 \pm 2.18$ & $5.89 \pm 1.55$ & $4.16 \pm 2.08$ & $6.87 \pm 1.80$ & $4.71 \pm 2.25$ \\
\hline Kiss & 2352.1 & $7.27 \pm 1.79$ & $5.16 \pm 2.17$ & $6.77 \pm 1.81$ & $4.98 \pm 1.97$ & $7.57 \pm 1.72$ & $5.28 \pm 2.29$ \\
\hline Bloody kiss & 2352.2 & $2.09 \pm 1.50$ & $6.25 \pm 2.10$ & $2.41 \pm 1.59$ & $5.78 \pm 1.94$ & $1.87 \pm 1.41$ & $6.57 \pm 2.16$ \\
\hline Open grave & 3005.1 & $1.63 \pm 1.19$ & $6.20 \pm 2.54$ & $1.96 \pm 1.44$ & $5.55 \pm 2.55$ & $1.35 \pm 0.85$ & $6.74 \pm 2.41$ \\
\hline Gold & 3005.2 & $5.98 \pm 1.90$ & $4.84 \pm 2.18$ & $6.10 \pm 1.64$ & $4.64 \pm 2.06$ & $5.87 \pm 2.13$ & $5.03 \pm 2.28$ \\
\hline
\end{tabular}

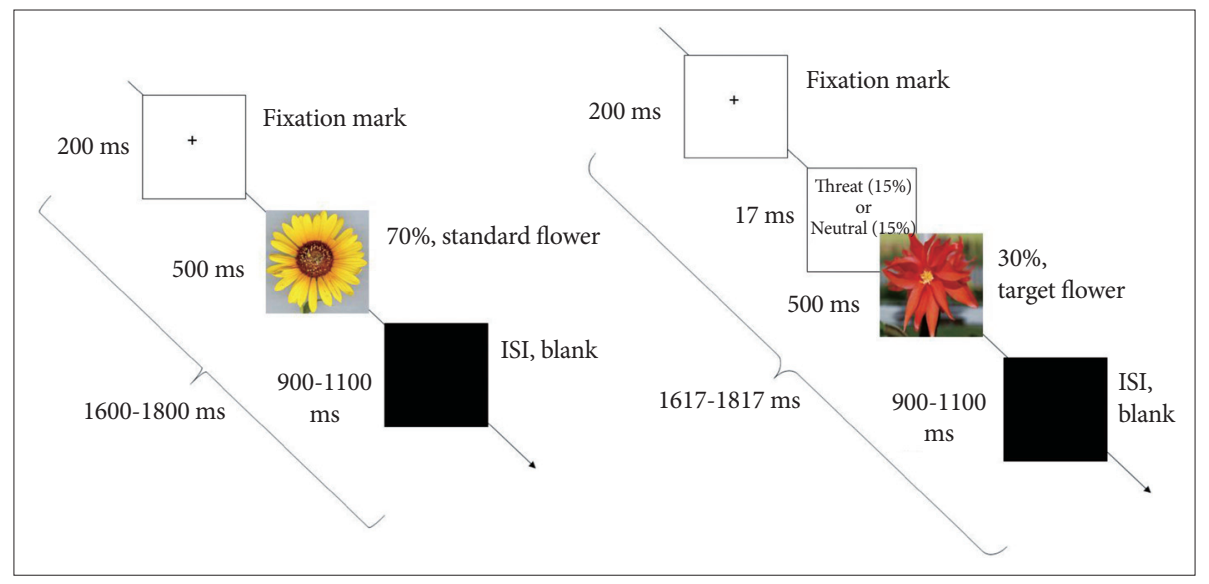

Figure 1. Illustration of study paradigm sequence. After a 200-ms fixation mark, either standard yellow flowers (70\%) or target red flowers $(30 \%)$ were presented at random for $500 \mathrm{~ms}$. The threat-related stimuli $(15 \%)$ or neutral stimuli $(15 \%)$ were presented for $17 \mathrm{~ms}$ and were masked by red target flowers. After the flower stimuli, a black screen was presented for $900-1100 \mathrm{~ms}$ as an interstimulus interval (ISI).

background image. IAPS pictures number 2055.1 and 2055.2 each depict a man's face. IAPS pictures number 2352.1 and 2352.2 depict a man and a woman who are kissing. IAPS pictures number 3005.1 and 3005.2 depicted a dead child's face and gold blocks, respectively. The stimuli were matched for luminescence and contrast.

We used the modified oddball paradigm in which standard stimuli (sun flower) were presented 210 times for $500 \mathrm{~ms}$ with the frequency of $70 \%$, and target stimuli (red flower) were presented 90 times with the frequency of $30 \%$. Among the red flower stimuli, the 6 pictures ( 3 threat-related vs. 3 neutral) were randomly inserted. The 6 pictures were presented 15 times (total 90 times) each for $17 \mathrm{~ms}$, which were subsequently masked by red flower for $500 \mathrm{~ms}$. It is important to note that the threshold of subliminal stimuli is significantly dependent on the participant's individual variation, study paradigm, and refresh rate of the monitor used in the study. Different studies that investigated the subliminal processing presented stimuli for different durations, depending on the refresh rate of the monitors. For instance, stimuli were presented for $8 \mathrm{~ms}$ (with a backward mask) on a CRT monitor with a $120 \mathrm{~Hz}$ refresh rate, $10 \mathrm{~ms}$ (with mask) on a SVGA monitor with a $100 \mathrm{~Hz}$ refresh rate, ${ }^{17}$ or $17 \mathrm{~ms}$ (with a backward mask) on a CRT monitor with a $60 \mathrm{~Hz}$ refresh rate. ${ }^{44}$ The oddball paradigm was chosen because this paradigm has been well-studied before and is theoretically well-constructed. Target stimuli receive attention in the oddball paradigm. We intended to analyze the subliminal processing of hidden stimuli below the target stimuli. Participants were instructed to press the button as soon as they saw the red flower. The P300 oddball target-detection task is a simple method to hold the attention of the participants (Figure 1).

The 17-inch CRT monitor (Samsung CD197GP; 60 Hz refresh rate) was used. The $17 \mathrm{~ms}$ was the shortest presentation duration permitted in the monitor $(1000 \mathrm{~ms} / 60=16.7 \mathrm{~ms})$. Stimuli were presented on the monitor positioned $1 \mathrm{~m}$ in front of the participants and subtended a maximum visual angle of $4 \times 4^{\circ}$. The trials started with a fixation cross presented for 200 $\mathrm{ms}$ followed by emotional stimuli presented for $17 \mathrm{~ms}$.

After flowers were presented, a black screen displayed for 900-1100 ms. Thus, the total duration of each trial was 1600$1817 \mathrm{~ms}$. The recording session of each participant lasted approximately 15 minutes. All participants were instructed to press the button by the right thumb while a blank screen was presented after target stimuli. Otherwise, they were instructed not to respond. After the task, subjects were asked whether 
they could discriminate fearful and neutral stimuli. Nobody reported seeing anything before the targets. To reaffirm this issue, we conducted another behavioral task in a different group ( $\mathrm{n}=24,12$ female participants). After the visual presentation of the same condition, subjects were asked whether they could discriminate fearful and neutral stimuli by using a 5-step visual analog scale [-2 (never seen), -1 (not seen), 0 (controversial), 1 (seen), 2 (absolutely seen)]. None of the participants reported seeing anything before the targets. All subjects reported -2 to 0 points.

\section{EEG recording}

Stimuli were presented and the EEG was synchronized to the onset of stimulus presentation using E-Prime (Psychology Software Tools, Pittsburgh, PA, USA). EEG activity was recorded and amplified using a Neuroscan NuAmps amplifier (Compunedics USA, El Paso, TX, USA) with $21 \mathrm{Ag} / \mathrm{Agcl}$ electrodes (Fz, Cz, Pz, Fp1/2, F3/4, F7/8, C3/4, T3/4, T5/6, P3/4, $\mathrm{O} 1 / 2, \mathrm{~A} 1 / 2)$ using a 10-20 placement scheme. The vertical electro-oculogram (EOG) was recorded using two electrodes, one located above and one below the left eye. The horizontal EOG was recorded at the outer canthi of each eye. The references were both mastoids. EEG data were recorded at 1000$\mathrm{Hz}$ sampling rate with a $0.1-100 \mathrm{~Hz}$ band-pass filter.

EEG data were initially processed using Scan 4.3. EEG data were re-referenced offline to an average reference. Eye blinks were removed from the data using established mathematical procedures. ${ }^{45}$ Trials were rejected if they included significant physiological artifacts (amplitude exceeding $\pm 70 \mu \mathrm{V}$ ) at all electrode sites. After artifact removal, baseline correction was conducted by subtracting the mean of $100 \mathrm{~ms}$ of pre-stimulus data from the post-stimulus data for each trial. Data were band pass filtered at $1-30 \mathrm{~Hz}$ then epoched to $100 \mathrm{~ms}$ pre-stimulus and $900 \mathrm{~ms}$ post-stimulus.

All participants showed excellent performance on the target detection. The sufficient number of accepted ERP epochs was obtained for all conditions and the averaged acceptance rate did not differ significantly between conditions (for threat-related stimuli, males vs. female $=42.40 \pm 2.22$ vs. $41.75 \pm 3.76$, $\mathrm{p}=\mathrm{ns}$; in neutral stimuli, males vs. female $=43.20 \pm 2.15$ vs. $41.83 \pm 3.61, \mathrm{p}=\mathrm{ns})$.

\section{Data analysis}

A grand-average waveform for each electrode within groups was obtained by averaging all epochs across participants. To determine the time windows for peak detection, we analyzed the mean global field potential (GFP) for each ERP component on grand averaged data across the condition in all of the participants. ${ }^{46}$ The final time windows were determined based on the maximal time window from scalp topography of
GFP and from previous studies. ${ }^{34,35,46}$ Based on the scalp topography of GFP, the target components for the present study were determined as following: P100, N170, N250, and P300.

Electrodes for subsequent analyses were chosen based on maximal activity displayed by two-dimensional scalp topographies for each ERP component. The peak amplitude and latency of P100, N170, N250 and P300 were determined by calculating the peak amplitude and mean latency (mean latency \pm one standard deviation) of each ERP component on averaged data across the condition in all of the participants. The time windows and electrodes of each component are as follows: $\mathrm{P} 100$ at lateral occipital electrodes $(\mathrm{O} 1 / \mathrm{O} 2)$ in the 43 $143 \mathrm{~ms}$, the N170 at temporal electrodes (T5/T6) in the 110210 ms time window, the $\mathrm{N} 250$ at central electrodes $(\mathrm{C} 3 / \mathrm{Cz} /$ $\mathrm{C} 4)$ in the time window of $160-360 \mathrm{~ms}$, and P300 at posterior electrodes $(\mathrm{P} 3 / \mathrm{Pz} / \mathrm{P} 4)$ in the time window of 300-450 ms.

The time windows of EPN and LPP were determined based on previous studies ${ }^{33,34,37,38}$ as follows: 1) previous known time ranges of EPN (150-300 ms) and LPP (300 ms-), 2) detecting deflection points of ERP waves on supposed electrodes sites, and 3) confirming with topographic maps.

The mean amplitudes of the EPN and the LPP were obtained at the posterior electrodes $(\mathrm{O} 1 / \mathrm{O} 2)$ in the time window of $150-240 \mathrm{~ms}$ and at posterior electrodes $(\mathrm{P} 3 / \mathrm{Pz} / \mathrm{P} 4)$ in the time window of 700-900 ms, respectively, after stimulus onset.

\section{Statistics}

Prior to statistical analysis, the data were tested for homogeneity of variance. Because the data met the assumptions required for the analysis of variance, the data were analyzed by repeated measures ANOVA for each component with electrode sites and stimuli types as within-subject and gender as between-subject factors. Mauchley's test evaluated the sphericity assumption. Correction of the degrees of freedom was made by the Greenhouse-Geisser procedure (for simplicity, the uncorrected degrees of freedom are presented). Post hoc comparisons were conducted using t-tests.

\section{RESULTS}

\section{Behavioral data}

The task was too simple for the normal healthy adults and all the participants performed it perfectly. Data for error rates and response times were not considered further because it is reasoned that the delayed behavioral response may not properly reflect the differences in the neural processing in the task. Given that stimulus discrimination and response selection are thought to occur in the 200-300 ms range, it seems likely that affective visual stimuli would trigger neural activations before executing behavioral responses. ${ }^{48}$ The level of anxiety and 
depression did not differ between the groups: BDI (male vs. female $=3.7 \pm 1.2$ vs. $2.9 \pm 2.7, \mathrm{p}=0.68$ ) and BAI (male vs. female= $3.5 \pm 2.6$ vs. $3.0 \pm 1.2, \mathrm{p}=0.86$ ).

\section{ERP analyses}

P100

There was no main effects of condition, site or gender on P100 amplitude were observed. None of the interactions were significant.

\section{N170}

There was no main effect of stimuli, site or gender on N170 amplitude. However, a significant two-way interaction between stimuli and gender was obtained $[\mathrm{F}(1,22)=6.94, \mathrm{p}=0.015]$.
Further analysis indicated that the N170 in response to threatrelated stimuli was greater compared to neutral stimuli in female participants $(-4.79 \pm 0.89 \mu \mathrm{V}$ vs. $-3.46 \pm 0.85 \mu \mathrm{V}$, respectively, $\mathrm{p}=0.019$ )(Figure 2 ) whereas no difference between threatrelated and neutral stimuli was observed in male participants $(-3.72 \pm 0.89 \mu \mathrm{V}$ vs. $-3.95 \pm 0.86 \mu \mathrm{V}$, respectively, $\mathrm{p}=0.503$ )(Figure 2). The interaction between electrodes sites and stimuli was also significant $[\mathrm{F}(1,22)=11.85, \mathrm{p}=0.002]$. Further analysis indicated that the N170 response to threat-related stimuli was greater relative to neutral stimuli at T5 $(-4.09 \pm 0.57 \mu \mathrm{V}$ vs. $-3.09 \pm$ $0.50 \mu \mathrm{V}$, respectively, $\mathrm{p}=0.012)$, but not at $\mathrm{T} 6(-4.42 \pm 0.76 \mu \mathrm{V}$ vs. $-4.32 \pm 0.76 \mu \mathrm{V}$, respectively, $\mathrm{p}=0.78$ ).

\section{$\mathrm{N} 250$}

The main effect of electrodes sites on the amplitude of N250

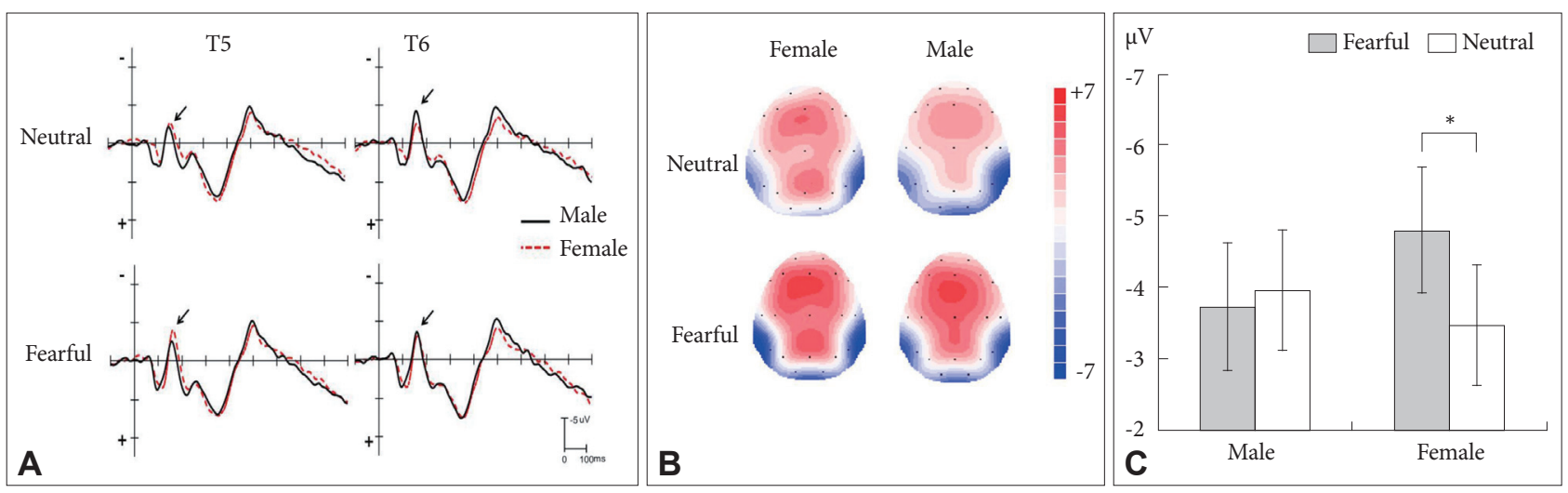

Figure 2. A: Grand-averaged event-related potential (ERP) waveforms of the N170 components elicited at electrodes T5 and T6 in response to subliminally presented threat-related and neutral stimuli. The solid and dashed waves indicate the male and female respectively. The arrows indicate the peak amplitudes of N170. B: Topographic maps are indicating the cortical activities at 163 ms point for subliminally presented threat-related and neutral stimuli in male and female subjects. C: The mean peak amplitude and standard errors of the N170 component for male and female participants in response to subliminally presented threat-related and neutral stimuli. Male participants did not show any significant difference between threat-related and neutral stimuli while female subjects showed a significant increase in the amplitude of the N170 component in response to threat-related stimuli. ${ }^{*} \mathrm{p}<0.05$.
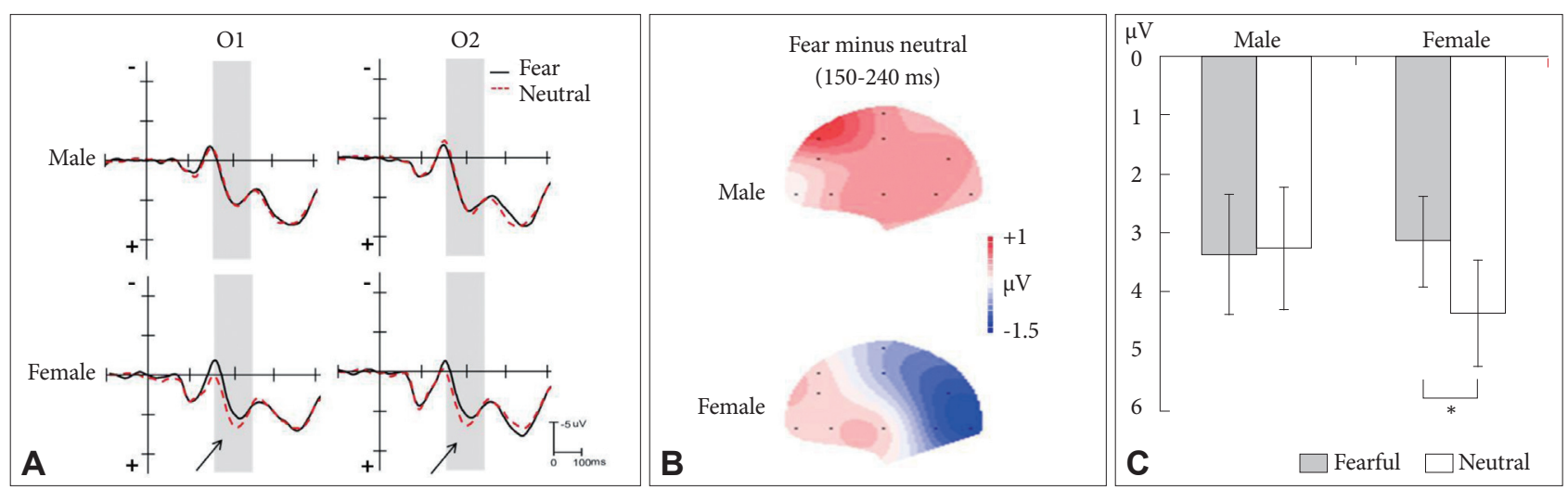

Figure 3. A: Grand-averaged event-related potential (ERP) waveforms of early posterior negativity (EPN) at electrodes $01 / \mathrm{O} 2$ in response to subliminally presented threat-related and neutral stimuli. The solid and dashed waves indicate the threat-related and neutral stimuli respectively. ERP activity inside of the gray bars represents the EPN. The arrows indicate the EPN effect on female subjects. B: Topographic maps are indicating the cortical activities during 150-240 ms point for subliminally presented threat-related and neutral stimuli in male and female subjects. The typical EPN (posterior negativity and anterior positivity) was found in female subjects. C: The mean peak amplitude and standard errors of the EPN component for male and female participants in response to subliminally presented threat-related and neutral stimuli. Male participants did not show any significant difference between threat-related and neutral stimuli while female subjects showed a significant increase in the amplitude of the EPN component in response to threat-related stimuli. ${ }^{*} p<0.05$. 
was observed $[\mathrm{F}(2,44)=8.44, \mathrm{p}=0.001]$. Post hoc analyses revealed that the $\mathrm{N} 250$ response at midline $\mathrm{Cz}$ was greater than those at $\mathrm{C} 3$ or $\mathrm{C} 4(-4.08 \pm 0.67 \mu \mathrm{V},-5.06 \pm 0.82 \mu \mathrm{V},-3.97 \pm 0.76$ $\mu \mathrm{V}$ at $\mathrm{C} 3, \mathrm{Cz}$, and $\mathrm{C} 4$ respectively). No other main effects or interactions were significant.

\section{P300}

The significant main effect of electrodes sites on P300 amplitude was observed $[\mathrm{F}(2,44)=17.56, \mathrm{p}=0.000]$. Post hoc analyses revealed that $\mathrm{P} 300$ activity at midline $\mathrm{Pz}$ was greater than that at $\mathrm{P} 3$ or at $\mathrm{P} 4(11.81 \pm 0.69 \mu \mathrm{V}, 13.63 \pm 0.81 \mu \mathrm{V}, 12.55 \pm$ $0.67 \mu \mathrm{V}$ at $\mathrm{P} 3, \mathrm{Pz}$, and $\mathrm{P} 4$, respectively). There was a significant interaction between electrodes sites and stimuli $[\mathrm{F}(2,44)=$ 10.64, $\mathrm{p}=0.001]$. The $\mathrm{P} 300$ response to threat-related stimuli was greater at $\mathrm{Pz}$ relative to neutral stimuli $(14.19 \pm 0.87 \mu \mathrm{V}$ vs. $13.08 \pm 0.81 \mu \mathrm{V}$, respectively, $\mathrm{p}=0.031$ ) whereas no difference was found at other sites. However, this small effect was disappeared after Bonferroni correction.

\section{EPN (mean amplitude of 150-240 ms)}

The significant main effect of stimuli was obtained. The EPN amplitudes differed by stimuli $[\mathrm{F}(1,22)=6.08, \mathrm{p}=0.022]$. Threat-related stimuli elicited significantly increased EPN amplitude relative to neutral stimuli $(3.27 \pm 3.10 \mu \mathrm{V}$ vs. $3.82 \pm$ $3.41 \mu \mathrm{V}$, respectively, $\mathrm{p}=0.044$ ). There was a significant twoway interaction between stimuli and gender $[\mathrm{F}(1,22)=8.67$, $\mathrm{p}=0.007]$. Further analysis indicated that the EPN in response to threat-related stimuli was greater compared to neutral stimuli in female participants $(3.16 \pm 2.67 \mu \mathrm{V}$ vs. $4.38 \pm 3.21 \mu \mathrm{V}$, respectively, $\mathrm{p}=0.005$ )(Figure 3 ) whereas no difference between threat-related and neutral stimuli was observed in male participants $(3.38 \pm 3.59 \mu \mathrm{V}$ vs. $3.27 \pm 3.66 \mu \mathrm{V}$, respectively, $\mathrm{p}=$ 0.719)(Figure 3).

\section{LPP (mean amplitude of 700-900 ms)}

There were no main effects of site, condition, and gender on the LPP response. None of the interactions were significant.

\section{DISCUSSION}

Women are capable of processing emotional stimuli more effectively than men, yet more women are suffering from affective disorders. ${ }^{2}$ To our best knowledge, this is the first study that investigates the gender effects on ERP responses to subliminally presented emotional stimuli. Only in female participants were greater N170 and EPN observed in response to threat-related stimuli relative to neutral stimuli. The current research suggests that female participants demonstrate the superior ability to process subliminally presented threat-related stimuli compared to male participants.

\section{N170}

Our results showed that female participants had increased N170 amplitudes for subliminally presented threat-related stimuli compared to male participants. Our stimuli contained human faces and it is well known that human faces evoke the N170 component. ${ }^{49}$ The N170 is typically associated with the structural encoding of faces. ${ }^{20,50} \mathrm{~A}$ number of studies have indicated that facial stimuli elicited greater amplitude of N170 compared to non-face objects or scrambled faces. ${ }^{51} \mathrm{~A}$ recent study provides evidence that the N170 is sensitive to subliminally presented fearful and threat-related faces. Pegna et al. ${ }^{12}$ reported that subliminally presented fearful faces elicited a stronger posterior negativity at $170 \mathrm{~ms}$ (N170) than non-fearful faces. Jiang et al. ${ }^{52}$ found that even in the invisible condition, fearful faces evoked significantly larger N170 along lateral superior temporal areas compared to neutral face. Carlson and Reinke ${ }^{16}$ also reported that masked fearful faces enhanced the N170 amplitudes of occipito-temporal electrodes.

Our finding suggests that the N170 is responsive to subliminally presented threat-related stimuli, but only in female participants. A recent study reported gender differences in the hemispheric lateralization of the N170 component. ${ }^{53}$ The N170 responses were bi-lateralized in women whereas a right hemispheric dominance of the N170 component was observed in men..$^{53}$ Similarly, Lee et al. ${ }^{20}$ reported a significant gender effect on the N170 latency in healthy controls and schizophrenia patients, such that the N170 latency in the male was longer than that in the female. Thus, it appears that the N170 component may be sensitive to gender differences and our results suggest that female participants exhibit greater N170 response to subliminally presented threat-related stimuli.

The enhanced processing of subliminal threat stimuli has been associated with affective disorders, such as anxiety. ${ }^{54} \mathrm{Am}$ ong women expecting gynecological examination, response latency on subliminally presented threatening words played an important role in predicting subsequent distress in response to the diagnosis. ${ }^{55,56}$ Therefore, it appears that the rapid processing of subliminally presented threat-related stimuli in female participants may be associated with vulnerability to stress or to psychopathology. ${ }^{57}$ Greater electrophysiological responses to subliminally presented threat-related stimuli in female participants may be associated with hypervigilance to threatening stimuli, which leads to greater vulnerability to affective disorders.

\section{EPN}

Our result revealed that subliminally presented threat-related stimuli provoked the enhanced EPN response. The EPN response is thought to reflect selective attention and the prioritized processing of affective stimuli, which occurs at the in- 
itial stage of the perceptual processing..$^{34}$ It has been suggested that emotion modulates activity of EPN, which occurs rather automatically without being affected by limited attentional resources. ${ }^{33,47}$ For instance, participants who were passively viewing emotional pictures while performing an emotion-irrelevant attentional task showed greater EPN. ${ }^{33}$ The result of our study is supporting automaticity of emotional modulation on the EPN. Additionally, in the present study, only female participants showed greater EPN responses to threat-related stimuli as compared to neutral stimuli, while male subjects did not show any differences. The result may indicate greater EPN responses to subliminally presented stimuli in female participants.

\section{P300}

In our study, the P300 component was not modulated by gender nor by emotion. Lang et al. ${ }^{58}$ reported that emotional facial stimuli elicited greater P300 amplitude compared to neutral face in visual oddball tasks in healthy individuals. Morita et al..$^{59}$ also reported greater P300 amplitude to negative emotional face compared to pleasure face. However, the studies using subliminal stimuli did not show the increased response for fearful stimuli compared to neutral stimuli. ${ }^{9,17}$ For instance, increased P300 amplitude was elicited only in supraliminal fearful faces condition, but not in subliminal condition. ${ }^{9,17}$

While some studies found significant gender effects on P300 activity in attentional tasks irrelevant to emotional processing, ${ }^{8,60}$ the present study did not find the gender effect on activity of the P300. Thus, the absence of gender effects on P300 activity in our study can be explained by several reasons. First, we used the subliminal stimuli whereas a P300 component is thought to be associated with processing supraliminal stimuli. P300 amplitude reflects the maintenance of working memory and is proportional to the amount of attentional resources devoted to a given task..$^{61}$ However, the subliminal stimuli do not require maintenance of working memory or the allocation of the attentional resource and therefore are not reflected on P300 activity. Second, the gender effect on P300 is not robust; there exists conflicting evidence of the gender effect on P300. ${ }^{31}$

\section{LPP}

There was no emotional modulation on the LPP although the LPP is thought to be responsive to affectively significant stimuli. ${ }^{62}$ The LPP reflects the late processing which occurs $300 \mathrm{~ms}$ after stimuli onset and usually indicates higher-level conscious evaluation and integration of affective information. ${ }^{9}$ Thus, it is reasonable that our subliminally presented stimuli do not affect the LPP that reflects the late processing of affectively significant stimuli.

\section{P100 \& N250}

There is accumulated evidence suggesting that P100 and N250 are generally larger for affectively significant stimuli.. ${ }^{20}$ However, in the present study, there was no significant difference in P100 and N250. In the oddball discrimination task, participants were passively viewing emotional stimuli while engaging in a non-emotional related task and previous studies reported that engaging in the non-emotion related target detection task may have reduced the emotion-modulation on early ERPs. ${ }^{21}$ Therefore, participants' involvement in a nonemotional related task may have resulted in a lack of emotional modulation on P100 and N250 in our study.

Employing constant objective threshold of awareness, which is $17 \mathrm{~ms}$ in this study, may be visible to some participants although no participant reported seeing the stimuli when asked after the task. The arousal level and valence for the emotional stimuli used were not rated in our participants, which would have provided more persuasive information.

\section{Conclusion}

The present study provides initial evidence that female participants show greater N170 and EPN responses to subliminally presented threat-related stimuli compared with neutral stimuli. However, there was no significant difference among P100 and N250, P300, or LPP. The present study suggests that early components in the occipitotemporal regions, such as $\mathrm{N} 170$ and EPN, reflect gender differences in the processing of emotional stimuli that are presented subliminally. Taken together, we show evidence that female participants show greater cortical processing of subliminally presented threat-related stimuli than male participants.

\section{Acknowledgments}

This work was supported by the National Research Foundation of Korea Grant funded by the Korean Government (NRF-2010-32A-B00282).

\section{REFERENCES}

1. Garcia-Garcia M, Domínguez-Borràs J, SanMiguel I, Escera C. Electrophysiological and behavioral evidence of gender differences in the modulation of distraction by the emotional context. Biol Psychol 2008; 79:307-316

2. Kemp AH, Silberstein RB, Armstrong SM, Nathan PJ. Gender differences in the cortical electorphysiological processing of visual emotional stimuli. Neuroimage 2004;21:632-646.

3. Bradley MM, Codispoti M, Sabatinelli D, Lang PJ. Emotion and motivation II: sex differences in picture processing. Emotion 2001;1:300-319.

4. Lane RD, Reiman EM, Bradley MM, Lang PJ, Ahern GL, Davidson RJ, et al. Neuroanatomical correlates of pleasant and unpleasant emotion. Neuropsychologia 1997;35:1437-1444.

5. Schneider F, Habel U, Kessler C, Salloum JB, Posse S. Gender differences in regional cerebral activity during sadness. Hum Brain Mapp 2000;9: 226-238.

6. George MS, Ketter TA, Parekh PI, Herscovitch P, Post RM. Gender differences in regional cerebral blood flow during transient self-induced 
sadness or happiness. Biol Psychiatry 1996;40:859-871.

7. Pardo JV, Pardo PJ, Raichle ME. Neural correlates of self-induced dysphoria. Am J Psychiatry 1993;150:713-719.

8. Steffensen SC, Ohran AJ, Shipp DN, Hales K, Stobbs SH, Fleming DE. Gender-selective effects of the P300 and N400 components of the visual evoked potential. Vision Res 2008;48:917-925.

9. Kiss M, Eimer M. ERPs reveal subliminal processing of fearful faces. Psychophysiology 2008;45:318-326.

10. LeDoux JE. Emotional memory: in search of systems and synapses. Ann N Y Acad Sci 1993;702:149-157.

11. Ohman A, Carlsson K, Lundqvist D, Ingvar M. On the unconscious subcortical origin of human fear. Physiol Behav 2007;92:180-185.

12. Pegna AJ, Landis T, Khateb A. Electrophysiological evidence for early non-conscious processing of fearful facial expressions. Int J Psychophysiol 2008;70:127-136.

13. Pessoa L, Japee S, Ungerleider LG. Visual awareness and the detection of fearful faces. Emotion 2005;5:243-247.

14. Morris JS, Öhman A, Dolan RJ. Conscious and unconscious emotional learning in the human amygdala. Nature 1998;393:467-470.

15. Whalen PJ, Rauch SL, Etcoff NL, Nclnerney SC, Lee MB, Jenike MA. Masked presentations of emotional facial expressions modulate amygdala activity without emplicit knowledge. J Neurosci 1998;18:411-418.

16. Carlson JM, Reinke KS. Spatial attention-related modulation of the N170 by backward masked fearful faces. Brain Cogn 2010;73:20-27.

17. Liddell BJ, Williams LM, Rathjen J, Shevrin H, Gordon E. A temporal dissociation of subliminal versus supraliminal fear perception: an event-related potential study. J Cog Neurosci 2004;16:479-486.

18. Williams LM, Liddell BJ, Rathjen J, Brown KJ, Gray J, Phillips M, et al. Mapping the time course of nonconscious and conscious perception of fear: an integration of central and peripheral measures. Hum Brain Mapp 2004;21:64-74.

19. Campanella S, Quinet P, Bruyer R, Crommelinck M, Guerit JM. Categorical perception of happiness and fear facial expressions: an ERP study. J Cogn Neurosci 2002;14:210-227.

20. Lee SH, Kim EY, Kim S, Bae SM. Event-related potential patterns and gender effects underlying facial affect processing in schizophrenia patients. Neurosci Res 2010;67:172-180.

21. Rozenkrants B, Polich J. Affective ERP processing in a visual oddball task: arousal, valence, and gender. Clin Neurophysiol 2008;119:22602265.

22. Batty M, Taylor MJ. Early processing of the six basic facial emotional expressions. Brain Res Cogn Brain Res 2003;17:613-620.

23. Carretie L, Hinojosa JA, Martin-Loeches M, Mercado F, Tapia M. Automatic attention to emotional stimuli: neural correlates. Hum Brain Mapp 2004;22:290-299.

24. Pourtois G, Grandjean D, Sander D, Vuilleumier P. Electrophysiological correlates of rapid spatial orienting towards fearful faces. Cereb Cortex 2004;14:619-633.

25. Bentin S, Allison T, Puce A, Perez E, McCarthy G. Electrophysiological Studies of Face Perception in Humans. J Cogn Neurosci 1996;8:551-565.

26. Jeffreys DA. A face-responsive potential recorded from the human scalp. Exp Brain Res 1989;78:193-202.

27. Turesky BI, Kohler CG, Indersmitten T, Bhati MT, Charbonnier D, Gur RC. Facial emotion recognition in schizophrenia: when and why does it go awry? Schizophr Res 2007;94:253-263.

28. Pfutze EM, Sommer W, Schweinberger SR. Age-related showing in face and name recognition: evidence from event-related brain potentials. Psychol Aging 2002;17:140-160.

29. Schweinberger SR, Pickering EC, Jentzsch I, Burton AM, Kaufmann JM. Event-related brain potential evidence for a response of inferior temporal cortex to familiar face repetitions. Brain Res Cogn Brain Res 2002; 14:398-409.

30. Tanaka JW, Curran T, Porterfield AL, Collins D. Activation of preexisting and acquired face representations: the N250 event-related potential as an index of face familiarity. J Cogn Neurosci 2006;18:1488-1497.
31. Oliver-Rodriguez JC, Guan Z, Johnston VS. Gender differences in late positive components evoked by human faces. Psychophysiology 1999; 36:176-185.

32. Polich J. Normal variation of P300 from auditory stimuli. Electroencephalogr Clin Neurophysiol 1986;65:236-240.

33. Schupp HT, Junghofer M, Weike AI, Hamm AO. Attention and emotion: an ERP analysis of facilitated emotional stimulus processing. Neuroreport 2003;14:1107-1110.

34. Schupp HT, Flaisch T, Stockburger J, Junghöfer M. Emotion and attention: event-related brain potential studies. Prog Brain Res 2006;156:31-51.

35. Lee TH, Lim SL, Lee JY, Choi JS. Facilitation of visual processing by masked presentation of a conditioned facial stimulus. Neuroreport 2009; 20:750-754.

36. Holmes A, Nielsen MK, Green S. Effects of anxiety on the processing of fearful and happy faces: an event-related potential study. Biol Psychol 2008;77:159-173.

37. Foti D, Hajcak G, Dien J. Differentiating neural responses to emotional pictures: evidence from temporal-spatial PCA. Psychophysiology 2009; 46:521-530.

38. Hajcak G, Olvet DM. The persistence of attention to emotion: brain potentials during and after picture presentation. Emotion 2008;8:250-255.

39. Hajcak G, MacNamara A, Olvet DM. Event-related potentials, emotion, and emotional regulation: an integrative review. Dev Neuropsychol 2010;35:129-155.

40. Beck AT, Ward CH, Mendelson M, Mock J, Erbaugh J. An inventory for measuring depression. Arch Gen Psychiatry 1961;4:561-571.

41. Beck AT, Epstein N, Brown G, Steer RA. An inventory for measuring clinical anxiety: psychometric properties. J Consult Clin Psychol 1988; 56:893-897.

42. First MB, Gibbon M, Spitzer RL, Williams JBW. User's Guide for the Structured Clinical Interview for DSM-IV Axis I Disorders - Research Version (SCID-1, Version 2.0, February 1996 Final Version). New York: Biometrics Research, New York State Psychiatric Institute; 1996.

43. Lang PJ, Bradley MM, Cuthbert BN. International affective picture system (IAPS): Affective ratings and instruction manual. Technical Report A-6. Florida: Gainesville, NIMH Center for the study of Emotion and Attention, University of Florida; 2005.

44. Eimer M, Kiss M, Holmes A. Links between rapid ERP responses to fearful faces and conscious awareness. J Neuropsychol 2008;2:165-181.

45. Semlitsch HV, Anderer P, Schuster P, Presslich O. A solution for reliable and valid reduction of ocular artifacts, applied to the P300 ERP. Psychophysiology 1986;23:695-703.

46. Hamburger HL, vd Burgt MA. Global field power measurement versus classical method in the determination of the latency of evoked potential components. Brain Topogr 1991;3:391-396.

47. Schupp HT, Stockburger J, Bublatzky F, Junghofer M, Weike AI, Hamm AO. Explicit attention interferes with selective emotion processing in human extrastriate cortex. BMC Neurosci 2007;22:8-16.

48. Olofsson JK, Polich J. Affective visual event-related potentials: arousal, repetition, and time-on-task. Biol Psychol 2008;75:101-108.

49. Thierry G, Pegna AJ, Dodds C, Roberts M, Basan S, Downing P. An event-related potential component sensitive to images of the human body. Neuroimage 2006;32:871-879.

50. Williams LM, Palmer D, Liddell BJ, Song L, Gordon E. The 'when' and 'where' of perceiving signals of threat and non-threat. Neuroimage 2006; 31:458-467.

51. Heisz JJ, Watter S, Shedden JM. Automatic face identity encoding at the N170. Vision Res 2006;46:4604-4614.

52. Jiang YI, Shannon RW, Vizueta N, Bernat EM, Patrick CJ, He S. Dynamics of processing invisible faces in the brain: automatic neural encoding of facial expression information. Neuroimage 2009;44:1171-1177.

53. Proverbio AM, Riva F, Martin E, Zani A. Face coding is bilateral in the female brain. PLoS One 2010;5:e11242.

54. Gatt JM, Clark CR, Kemp AH, Liddell BJ, Dobson-Stone C, Kuan S, et al. A genotype-endophenotype-phenotype path model of depressed 
mood: integrating cognitive and emotional markers. J Integr Neurosci 2007;6:75-104.

55. van den Hout M, Tenney N, Huygens K, Merckelbach H, Kindt M. Responding to subliminal threat cues is related to trait anxiety and emotional vulnerability: a successful replication of MacLeod and Hagan (1992). Behav Res Ther 1995;33:451-454.

56. MacLeod C, Hagan R. Individual differences in the selective processing of threatening information, and emotional responses to a stressful life event. Behav Res Ther 1992;30:151-161.

57. Mayer B, Merckelbach H. Unconscious processes, subliminal stimulation, and anxiety. Clin Psychol Rev 1999;19:571-590.

58. Lang SF, Nelson CA, Collins PF. Event-related potentials to emotional and neutral stimuli. J Clin Exp Neuropsychol 1990;12:946-958.

59. Morita Y, Morita K, Yamamoto M, Waseda Y, Maeda H. Effects of facial affect recognition on the auditory P300 in healthy subjects. Neurosci Res 2001;41:89-95.

60. Jeon YW, Polich J. Meta-analysis of P300 and schizophrenia: patients, paradigms, and practical implications. Psychophysiology 2003;40:684701.

61. Polich J. Updating P300: an integrative theory of P3a and P3b. Clin Neurophysiol 2007;118:2128-2148.

62. Schupp HT, Cuthbert BN, Bradley MM, Cacioppo JT, Ito T, Lang PJ. Affective picture processing: the late positive potential is modulated by motivational relevance. Psychophysiology 2000;37:257-261. 